\title{
The Museum of Mankind (British Museum), London
}

IN accordance with a recent decision of the Trustees of the British Museum, the building at 6 Burlington Gardens, London, W. I (immediately behind the Royal Academy) which has since December $197^{\circ}$ housed the exhibitions of the Ethnography Department of the British Museum will henceforth be known as The Museum of Mankind. The Department will continue to illustrate in its exhibitions the science of cultural anthropology in the broadest sense-including ethnography, the descriptive, and ethnology, the comparative, study of human cultures-and cover especially the life and arts of tribal peoples of the world.

The Ethnography Department has now begun the immense task of transferring most of the study collections, amounting to some 750,000 specimens, from cramped and often unsuitable quarters in the main British Museum building at Bloomsbury to an excellent repository in Orsman Road, Shoreditch, N. r, a task which will probably occupy at least the next two years. When the move is complete, facilities for students wishing to work on specimens will be better than ever before; however, during the intervening period it will often be difficult or impossible to give students all the help and facilities which the Department would like to provide.

\section{Leo Frobenius Centenary: Prize Competition}

To mark the Centenary of the birth of Leo Frobenius, the German UNESCO Commission together with the Frobenius Institute intend to hold an International Symposium in Africa, tentatively fixed for Autumn 1973. The Frobenius Institute also invites participation in a prize competition. Entry is restricted to Africans; the best fifteen articles on African culture and history are to be selected by an international jury and printed in a 'Festband' of Paideuma. The articles need not be concerned directly with Leo Frobenius, but should deal with current historical and cultural research and ideas in present-day Africa. They should be written in English or French and should not exceed 6,000 words in length. The last date for receipt of the manuscripts is 31 March 1973 . The authors of the five best articles will receive a three-month study and research grant and will be invited, together with the authors of the other accepted articles, to the Symposium 'History and Culture in Africa'. All inquiries and correspondence should be addressed to Professor Dr. Eike Haberland (Frobenius Institute), 6000 Frankfurt a. M., Liebigstrasse 4r, Germany.

\section{African Books in Print}

THE University of Ife Press is publishing a new reference tool project for book development in Africa: African Books in Print: an Index by Author, Title and Subject. The project is undertaken jointly with Richard Abel \& Company Inc., Portland, Oregon, who will handle marketing and distribution. Compiled with the assistance of a board of editorial consultants, it will be the first authoritative source of reference for books published in Africa currently in print. It will help to solve book-finding problems, provide guidance on the acquisition of these materials, and will include information about the African book and publishing trades. It is estimated that some 5,000 titles will be listed in volume one. Scheduled for publication in late 1973, this will cover all English language materials plus a selection of books in the vernacular languages. Volume two will cover books from francophone Africa as well as titles in Portuguese and Spanish.

\section{Social Research Center, The American University in Cairo: 1971/72 Reprint Series}

THe Social Research Center of the American University in Cairo has begun a Reprint Series. Lists of current reprints are scheduled for distribution on a semi-annual basis. 